\title{
Design Around Bundle Patent Portfolio Based on Technological Evolution
}

\author{
Hui Li ${ }^{1}$, Jiefeng Yuan ${ }^{1}$, Runhua Tan ${ }^{1 *}$ and Qingjin Peng ${ }^{2}$
}

\begin{abstract}
Product innovation can be achieved by analyzing leading products patents in the market. Different methods have been proposed for design around patent, commonly using the elimination or replacement of a single patent element. However, the existing research fails to restore the position and function of the design around object in the original patent portfolio of enterprises, which often leads to the phenomenon of evading one patent and violating another. This paper proposes a method for design around patent through using the fusion of technologies of the evolution theory and bundle-type patent portfolio analysis in the initial stage of product development. The object system is analyzed to select technical opportunities through the evolutionary path of technologies and functional trimming methods to achieve circumvent barriers of bundle-type patents. The bundle patent portfolio is analyzed for the product evolution with a radar map. The technological evolution path is combined with the TRIZ innovation method to identify and solve the design problem. Patentability of the new design is evaluated using the patent system rules for innovative scheme difference from the original patent portfolio. The method is verified in a case study for the design of a glass-wiping robot. The design solution has been patented.
\end{abstract}

Keywords: Design around patent, Bundle patent portfolio, TRIZ, Technological evolution, Inventive problem solving

\section{Introduction}

With the rapid development of technology and information sharing, patent information analysis is getting more important for innovation [1]. The patent analysis has been used for the industry development evaluation $[2-4]$, technology life cycle prediction $[5,6]$, research and development strategy formulation [7, 8], and patent value evaluation [9-13]. Enterprises have to build a clear intellectual property strategy to form a systematic patent barrier for a competitive advantage position of certain products in the market $[14,15]$. The product's technological opportunities can be identified by studying patent barriers of leading enterprises or competitors in the market to analyze their patent layout of the current state of technologies [16, 17]. Different patterns of patent portfolio layouts can be applied to research and development plans $[18,19]$. There are four types of patent portfolios

\footnotetext{
*Correspondence: rhtan@hebut.edu.cn

${ }^{1}$ National Technical Innovation Method and Tool Engineering Technology Research Center, Hebei University of Technology, Tianjin 300401, China Full list of author information is available at the end of the article
}

including umbrella, bundle, chain, and star types based on technical relations of patents, such as complementarity, competitiveness, supportability and extensibility. The umbrella type is a multi-problem patent portfolio scheme for a product system. The star type is for multi-system integration. The chain type is an industrial chain patent portfolio for the product life cycle. The bundle-type is a patent portfolio for a single problem [20-22]. Using a bundle-type patent portfolio, different solutions of the same problem form a complete protection for the patent to overcome limitations of a single patented technology protection with a certain technical problem. Essence of a design around bundle-type patent portfolio is to find an existing valuable technical problem of a product by using the innovative method to solve the problem with new solutions, which can form a new patented technology that competes with the original target product.

Laws of the technical evolution are a series of principles found by Altshuller of the existence, operation or change of a system [23]. He suggested that a same problem appears repeatedly in different technical fields, and the same principle of a solution can be repeatedly applied 
to different fields to solve similar problems. TRIZ's tools for problem analysis and problem solving are enlightened by different ways to solve technical problems in the real world [24, 25].

This paper proposes the fusion of technologies of the evolution theory and bundle-type patent portfolio analysis in the initial stage of product development. The object system is analyzed to select technical opportunities through the evolutionary path of technologies and functional trimming methods to achieve circumvent barriers of bundle-type patents. Goals are searching alternative solutions at a certain level of the product system through the technological evolutionary path, and solving the same problem based on different effect principles. It also uses the internal trimming replacement to achieve the deformed structure based on different product structures. The final solution forms a new way to solve the same problem with different principles, structures or circumvents based on the existing bundle patent portfolio.

\section{State of the Art}

\subsection{Design Around Bundle-Type Patent Portfolio}

Research on design around patent commonly focuses on the elimination or replacement of a single patent element under using design around patent principles. Different methods have been proposed by researchers. TRIZ is used as a means of supporting product designers to obtain patented strategic data [26]. Three opportunities are identified to guide inventors to find design around patent solutions through various recommended innovations and TRIZ tools [27]. Potential product opportunities are discussed beyond a given product area by processing large-scale technical patent data sets [28]. A trimming method is proposed based on TRIZ for the design around patent $[29,30]$. A design around patent process is developed using both TRIZ and WOIS [31]. Integrated TRIZ conflict matrix and conceptual design is applied to process modeling of the product design around [32,33]. An avoidance method is suggested using integrated TRIZ and existing patent technologies [34]. However, the existing research on the single design around patent fails to restore the position and function of the design around object in the original patent portfolio of enterprises, which often leads to the phenomenon of evading one patent and violating another. For the design around patent portfolio, a new framework is supported to extract patent portfolio strategic information [35]. IPC clustering analysis and maturity prediction are adopted to determine the patent portfolio avoidance target [36]. In fact, these methods only simplify a single patent to avoid the violation. They seldom consider differences and relations among internal patent portfolios. The design around purpose and meaning of the patent portfolio are not clear. On the other hand, they also ignore scopes of the patent right, the recognition accuracy of the right map is low.

There are two bases for success of the design around patent, the scope of patent rights and non-infringement of a new design. For scope of the patent right, it is required to understand patent technology problems based on the characteristics of the patent law document. Technical problems of a patent are determined by the difference of technical features of the existing proximal technology and actual effect of the problem solved by the patent [37].

Solutions to a technical problem are extracted from the independent claim. According to legal characteristics of the patent document, a complete technical scheme with independent claims of the patent has the full protection. The technical information in a patent document is closely related to its functional expression. A functional model diagram is proposed for describing the independent claim of a patent, which is composed of the super system, components, relationships of components, and products. The document information is transformed into a patent right map as shown in Figure 1 [38]. The super system is the environment that affects the system. The product is the output of the system to the environment. The component is the smallest element of the system. There are four types of connections among components: excess, standard, insufficient and harmful as shown in Figure 1.

Design solutions cannot be contrary to the doctrine of equivalents and universal coverage principle. There are four principles to be followed in practical applications: 1) deleting rule to remove technical features so as not to violate the principle of a full coverage, 2) Substituting rule to replace technical features without violating the principle of equivalence, 3) Changing rule of relationships to modify the connection and location of elements to not violate the universal coverage principle, and 4) Adding or combining rule to use the deletion and addition as a non-violation of the principle of the universal coverage and doctrine of equivalents [29, 30].

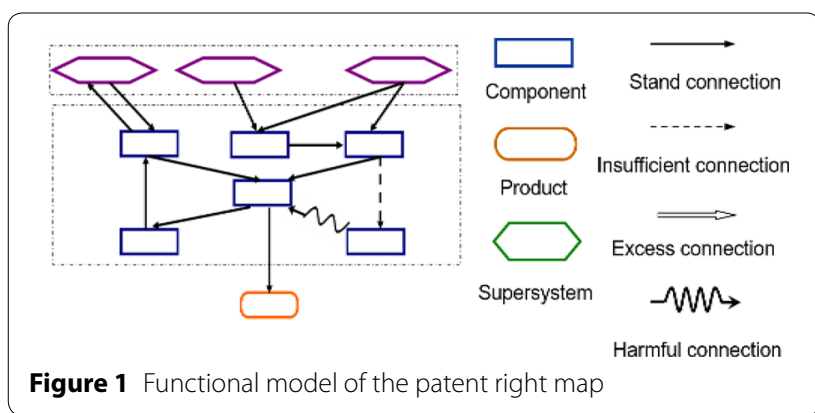


Patents in the bundle-type patent portfolio form a congeneric relation. Each patent has a competitive relationship with others. There are two types of the bundle-type patent portfolio as shown in Figure 2. Type A is composed of patents with different principles for the same problem. $\mathrm{P}_{\mathrm{A}}$ consists of structural modules $\mathrm{A} 1$ and $\mathrm{A} 2$. $\mathrm{P}_{\mathrm{B}}$ consists of structural modules $\mathrm{B} 1$ and $\mathrm{B} 2 . \mathrm{P}_{\mathrm{A}}$ and $\mathrm{P}_{\mathrm{B}}$ constitute the type A patent portfolio. Type $B$ is an integrated form of different structures to form a competitive bundle-type patent portfolio, $\mathrm{P}_{\mathrm{A}^{\prime}}, \mathrm{P}_{\mathrm{B}^{\prime}}$, and $\mathrm{P}_{\mathrm{C}^{\prime}}$ are three patents that solve the same problem with the same principle, but components of the problem solved are different, indicated by $A^{\prime}, B^{\prime}$ and $C^{\prime}$, respectively. $P_{A^{\prime}}, P_{B^{\prime}}$, and $\mathrm{P}_{\mathrm{C}}$, form the type $\mathrm{B}$ patent portfolio. The more competitive patents formed by a self-circumvention, the more patent protections will have for core technologies of an enterprise. Competitive technologies circumvented from others may participate in the market competition to cultivate advantages of the enterprise [39].

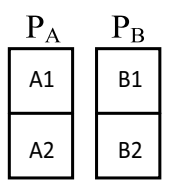

Type A

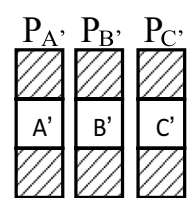

Type B
Figure 2 Two types of the bundle-type patent portfolio

\subsection{Law of Technological Evolution}

The law of technological evolution and its path in TRIZ are a kind of invention rules that prompt product development from the current principle to next stage [40, 41]. It is formed from a large number of invention patents in different fields. There are eight laws of technological evolution including: 1 ) increasing the idealization level; 2) unbalanced development of subsystems; 3) dynamization; 4) delivering to a complex system; 5) delivering to the microscopic system; 6) law of system integrity; 7) shortening the path length of the energy flow; and 8) increasing the coordination. Corresponding relationships of design around directions and laws of the evolution or some routes are summarized in Table 1 [42].

\section{Proposed Method}

\subsection{A General Process of Design Around Patent}

Figure 3 shows a design around process of bundle-type patent portfolios based on the law of technology evolution for a research object. The process includes four steps. The first step identifies barriers of a bundle-type patent portfolio; the second step searches a specific technological evolution route or makes function trimming in order to identify patent problems; the third step solves technical problems by technical conflict, material field analysis and effect theory; the fourth step verifies the validity of the patent portfolio.

Table 1 Relations of design around directions and evolution routes

\begin{tabular}{|c|c|c|}
\hline Circumvent direction & The role of system change & The corresponding law of evolution and route \\
\hline \multirow[t]{2}{*}{ Add or combine } & Add elements and contacts to the system & Integrity \\
\hline & Add elements and contacts to the system & Deliver to complex systems \\
\hline \multirow[t]{2}{*}{ Delete } & $\begin{array}{l}\text { Remove or partially remove elements and links from the } \\
\text { system }\end{array}$ & Increasing the idealization level -trimming \\
\hline & $\begin{array}{l}\text { Remove or partially remove elements and links from the } \\
\text { system }\end{array}$ & shortening the path length of the energy flow \\
\hline \multirow[t]{5}{*}{ Substitute } & Replace some elements of the system and contact & $\begin{array}{l}\text { The unbalanced development of subsystems-System expan- } \\
\text { sion }\end{array}$ \\
\hline & Divide the elements of the system into sections & Deliver to the microscopic system-Material segmentation \\
\hline & Change the shape and size of the system element & $\begin{array}{l}\text { The unbalanced development of subsystems-Material geom- } \\
\text { etry evolution }\end{array}$ \\
\hline & Change the internal structure of system elements & $\begin{array}{l}\text { The unbalanced development of subsystems- Material internal } \\
\text { structure evolution }\end{array}$ \\
\hline & Change the surface state of system elements & $\begin{array}{l}\text { The unbalanced development of subsystems- Material surface } \\
\text { characteristics of evolution }\end{array}$ \\
\hline \multirow{3}{*}{$\begin{array}{l}\text { Change the relation- } \\
\text { ship among param- } \\
\text { eters }\end{array}$} & $\begin{array}{l}\text { To ensure the mobility of all parts of the system and other } \\
\text { parameters of the variability }\end{array}$ & Dynamization \\
\hline & Ensure real-time control and simplify it & Dynamization \\
\hline & Check and improve the coordination of system elements & Increasing the coordination \\
\hline Change principle & Find effects again & $\begin{array}{l}\text { Deliver to the microscopic system-Deliver to field } \\
\text { Dynamic, flexible }\end{array}$ \\
\hline
\end{tabular}




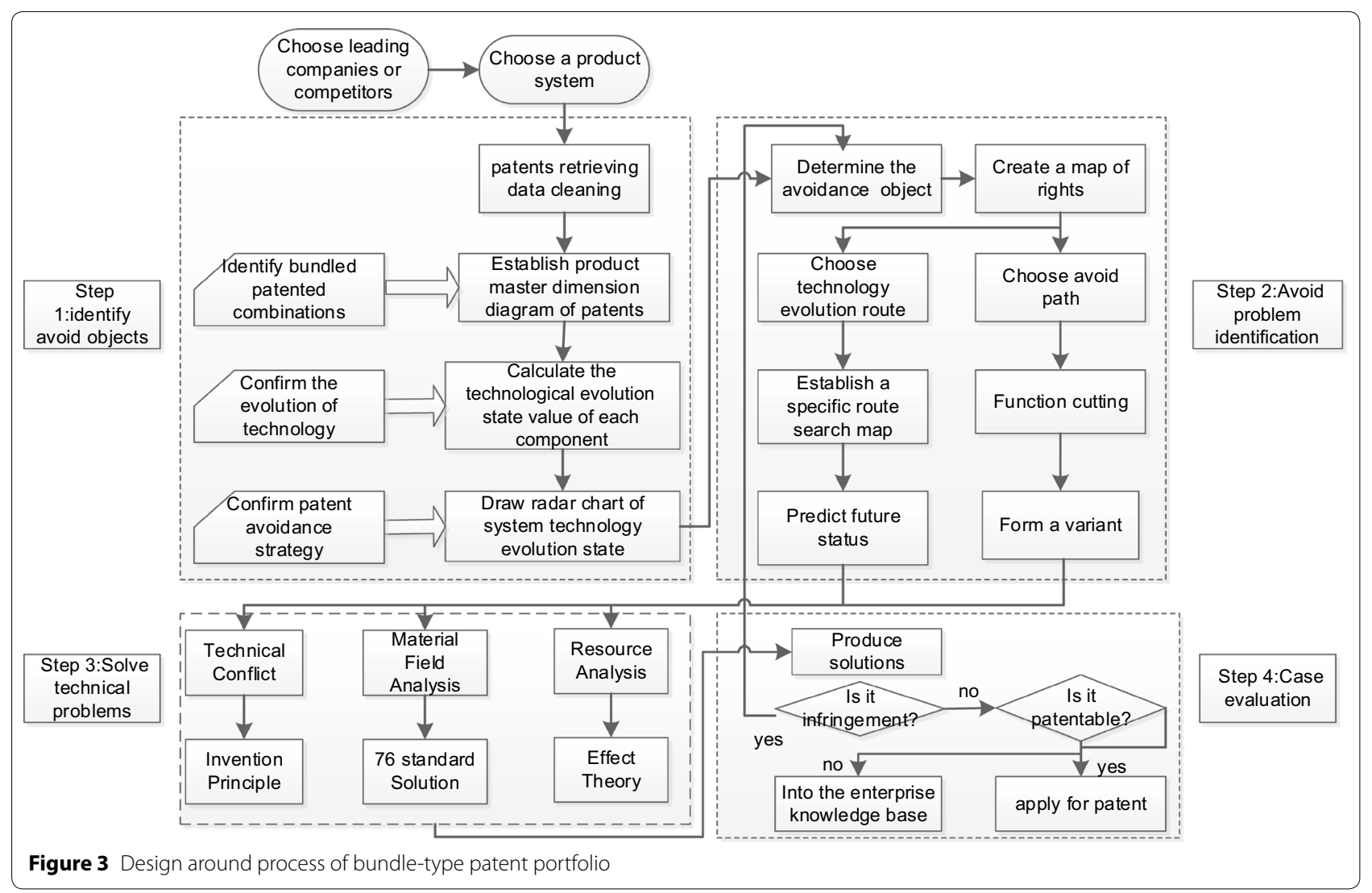

\subsection{Design Around Target Definition}

The object identification of the design around patent consists of three steps: 1 ) selecting the target enterprise's product and searching patents to identify their bundletype patent portfolio layouts; 2) analyzing the technological evolution of the bundle patent portfolio for the state of technological development value; 3) building a patent-based technology evolution radar chart of the target product, and selecting specific design around targets according to actual needs of the enterprise as follows.

Step 1: Selecting the target enterprise's product and searching patents to identify their bundle-type patent portfolio layouts, such as a product composed of components $\{\mathrm{A}, \mathrm{B}, \mathrm{C}\}$. The development state value of components $A, B$ and $C$ can be identified as follows.

1) Searching patents of the target product in leading enterprises, screening and summarizing the patents, marking patents of each component to obtain a patent group under different components. For example, the patent group of component $A$ is $\{A\}=\left\{A_{1}, A_{2}\right.$, $\left.\ldots, \mathrm{A}_{n}\right\}$.

2) Analyzing specific problems of the patent in each component to determine the problem module of existing solutions to establish the correspondence between the problem module and patent solution. For example, component $\mathrm{A}$ for the technical problem set is $\left\{T_{A}\right\}=\left\{A-T_{1}, A-T_{2}, \ldots, A-T_{j}\right\}$, indicating that the $j$ discovered system problems are under component A. According to technical problems, the patent is classified to set up a bundle patent portfolio analysis chart as shown in Figure 4.

Step 2: Calculating the development state of each component under the law of technological evolution to determine the state of the art. The development state of each component of the product system under different evolution laws is shown in Table 2.

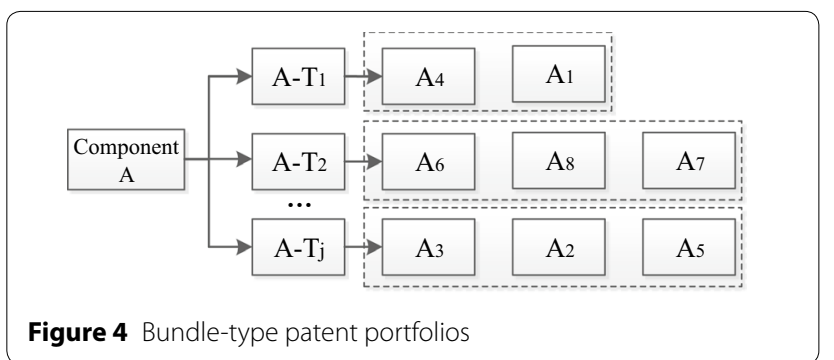


We first search the total number of patents $\mathrm{n}$ and the number of patents $n_{n}$ for different problems of each component of the product, and then determine the impact index $w_{j}$ of different problems, that is, $w_{j}=\left(\mathrm{A}-\mathrm{T}_{j}-n_{j}\right) / n$. $\mathrm{A}-\mathrm{T}_{n}-m_{i}$ represents the number of patents for the different technological evolution laws under $\mathrm{A}-\mathrm{T}_{j}$, where $i$ is the number corresponding to the law of evolutions 1 to 8 . Using the impact index and number of patents, the value of the development state of component $\mathrm{A}$ under different technological evolution laws can be determined to confirm the technological evolution state of different components of the target. The development state is calculated as follows:

$$
A-D_{i}=\sum_{j=1}^{j} w_{j}\left(A-\mathrm{T}_{j}-m_{i}\right),(i=1,2,3,4,5,6,7,8)
$$

where $m_{i}$ is the number of patents under different laws of technological evolution, $w_{j}$ represents the impact index of different problems, and $\mathrm{A}-\mathrm{D}_{i}$ is the component $\mathrm{A}$ development state value under No. $i$ technological evolution law. For example, component A solves three technical problems, $\mathrm{T}_{1}, \mathrm{~T}_{2}$ and $\mathrm{T}_{3}$. There are $\mathrm{n}$ patents in total. The number of patents for each technical problem is $n_{1}$, $n_{2}$ and $n_{3}$, respectively. $w_{1}, w_{2}$ and $w_{3}$ are $\left(\mathrm{A}-\mathrm{T}_{1}-n_{1}\right) / n$, $\left(\mathrm{A}-\mathrm{T}_{2}-n_{2}\right) / n,\left(\mathrm{~A}-\mathrm{T}_{1}-n_{3}\right) / n$, respectively. The number of patents for the application of technological evolution law 1 is $\mathrm{A}-\mathrm{T}_{1}-m_{1}, \mathrm{~A}-\mathrm{T}_{2}-m_{1}$, and $\mathrm{A}-\mathrm{T}_{3}-m_{1}$. The development state of component $\mathrm{A}$ under the law of technological evolution is $\mathrm{A}-\mathrm{D}_{1}=w_{1}^{*}\left(\mathrm{~A}-\mathrm{T}_{1}-m_{1}\right)+$ $w_{2}{ }^{*}\left(\mathrm{~A}-\mathrm{T}_{2}-m_{1}\right)+w_{3}{ }^{*}\left(\mathrm{~A}-\mathrm{T}_{3}-m_{1}\right)$.

Step 3: Drawing a radar chart of the product technology evolution state to select the circumvent direction.
Development state values of different components are calculated under the eight laws of technological evolution using Eq. (1). A radar chart is formed as shown in Figure 5. Based on evolutionary states of technologies in the radar chart, we can clearly find the state and future of development space for the product system under different laws of the technological evolution, which can be used to compare development state values of different components. Different products of the design around object can be selected for development strategies as follows.

1) Different avoidance components and laws are chosen according to actual needs of enterprises and resource allocations.

2) The design around direction can be decided based on components that are backward in all directions of evolution. A bundle-type patent portfolio is selected to solve a technical problem as the design around object. A technological evolution direction with less development can be identified for the development.

\subsection{Design Around Problem Identification}

The problem identification of design around patent involves two steps as follows.

1) Creating a patent right map. The map shows a set of patent solutions to a technical issue of the target problem as shown in Figure 1. The aim is to obtain protected technical schemes of the target object.

2) Identifying and analyzing problems in two types of bundle-type patent portfolios.

Table 2 Product system components in different technological evolution laws under the state of development

\begin{tabular}{|c|c|c|c|c|c|}
\hline $\begin{array}{l}\text { Component-the number } \\
\text { of patents }\end{array}$ & $\begin{array}{l}\text { Number of patents } \\
\text { corresponding } \\
\text { to the question }\end{array}$ & Impact index $w_{j}$ & $\begin{array}{l}\text { The law of technological } \\
\text { evolution }\end{array}$ & Number of patents $m_{i}$ & State value $D_{i}$ \\
\hline \multirow[t]{8}{*}{$A-n$} & \multirow[t]{3}{*}{$\mathrm{A}-\mathrm{T}_{1}-n_{1}$} & \multirow[t]{3}{*}{$W_{1}=\frac{A-T_{1}-n_{1}}{n}$} & $\begin{array}{l}1 \text { (Increasing the idealization } \\
\text { level) }\end{array}$ & \multirow[t]{3}{*}{$\mathrm{A}-\mathrm{T}_{1}-m_{i}$} & $A-D_{1}$ \\
\hline & & & $\begin{array}{l}2 \text { (The unbalanced develop- } \\
\text { ment of subsystems) }\end{array}$ & & $A-D_{2}$ \\
\hline & & & 3 (Dynamization) & & $A-D_{3}$ \\
\hline & \multirow[t]{3}{*}{$A-T_{2}-n_{2}$} & \multirow[t]{3}{*}{$W_{1}=\frac{A-T_{2}-n_{2}}{n}$} & $\begin{array}{l}4 \text { (Delivering to a complex } \\
\text { system) }\end{array}$ & \multirow[t]{3}{*}{$\mathrm{A}-\mathrm{T}_{2}-m_{i}$} & $A-D_{4}$ \\
\hline & & & $\begin{array}{l}5 \text { (Delivering to the micro- } \\
\text { scopic system) }\end{array}$ & & $A-D_{5}$ \\
\hline & & & 6 (Integrity) & & $A-D_{6}$ \\
\hline & \multirow[t]{2}{*}{$\mathrm{A}-\mathrm{T}_{j}-n_{j}$} & \multirow[t]{2}{*}{$w_{j}=\frac{A-T_{j}-n_{j}}{n}$} & $\begin{array}{l}7 \text { (Shortening the path } \\
\text { length of the energy flow) }\end{array}$ & \multirow[t]{2}{*}{$\mathrm{A}-\mathrm{T}_{3}-m_{i}$} & $A-D_{7}$ \\
\hline & & & $\begin{array}{l}8 \text { (Increasing the coordina- } \\
\text { tion) }\end{array}$ & & $A-D_{8}$ \\
\hline
\end{tabular}




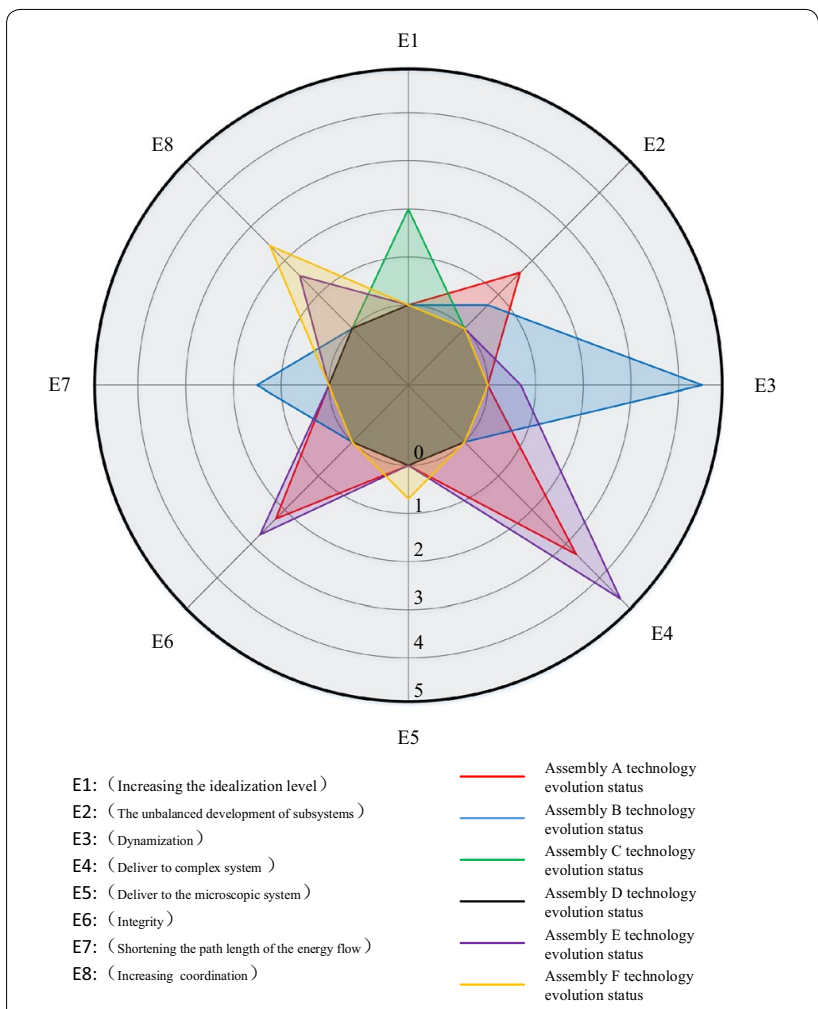

Figure 5 Product system technology evolution state radar chart

For type A portfolio: a search map of the technological evolution path is built as shown in Figure 6. The TRIZ theory reveals eight laws of the technological development and evolution. There are several specific routes under each law of the technological evolution. The technical principle of the same problem can be predicted in the selected route of technological evolution by determining the current state of the product. For example, technological evolution paths 2-4 can be selected under law 2 to evolve from states 1 to 5 . Current state 3 is correctly located to predict the development path and implementation principles of state 4 or 5 in the next stage. The principles give designers ideas for the unification problem to generate new concepts.

For type B portfolio: a design around path is chosen for function trimming to generate design variants. According to the patent right map of the object, a specific clipping path can be selected in Table 3 for the function trimming to obtain variants, and transform the problem into a new design problem.

\subsection{Problem Solving}

Two types of problem deformations can be obtained from Section 3.3. After the problem identification, these two types of problems are transformed into TRIZ standard problems. Different problems can then be solved with the corresponding knowledge of TRIZ [43-46]. There are three types of standard problems and corresponding solutions. The first one is standard questions described by the material field, and 76 standard solutions; the second is conflict problems described by standard engineering parameters and solutions of 40 invention principles; and the third is inspiration proposals from function searching and knowledge base. Conceptual solutions can be proposed based on the standard solution principle

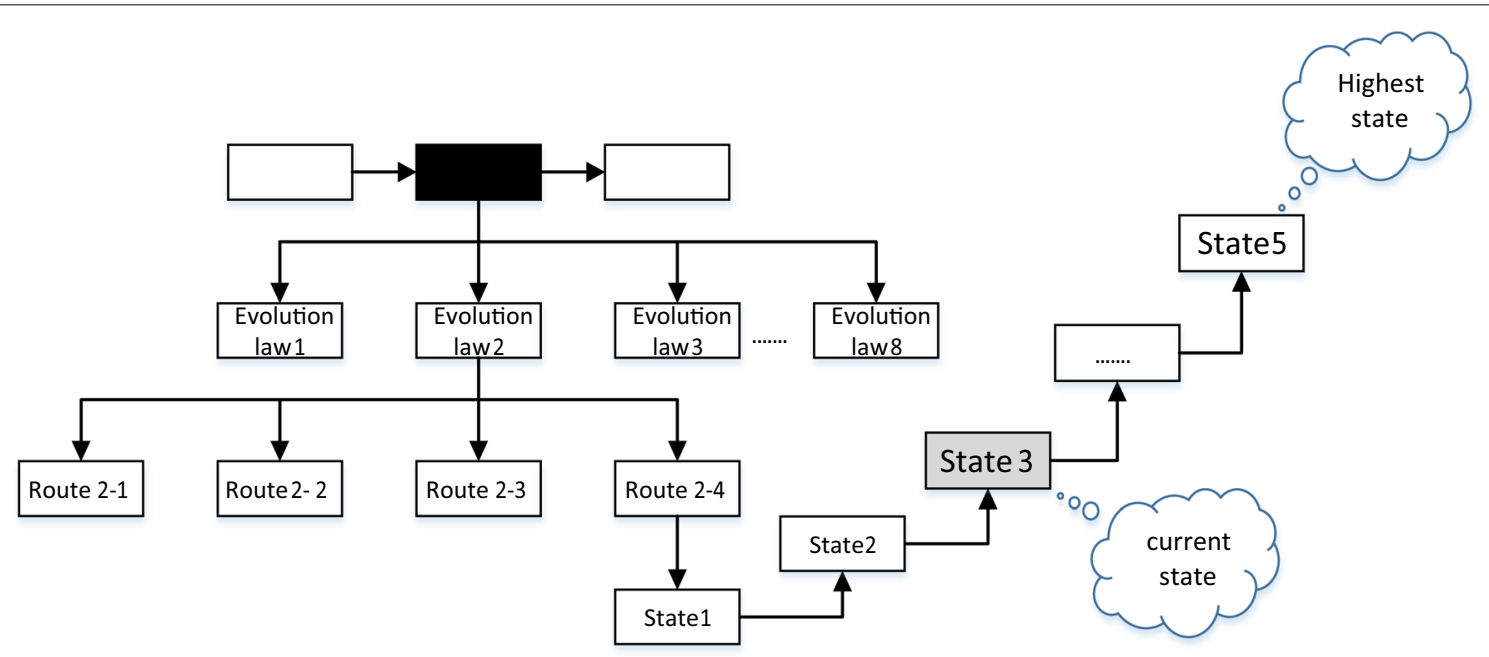

Figure 6 Search map of the product technological evolution path 
Table 3 Design around patent path

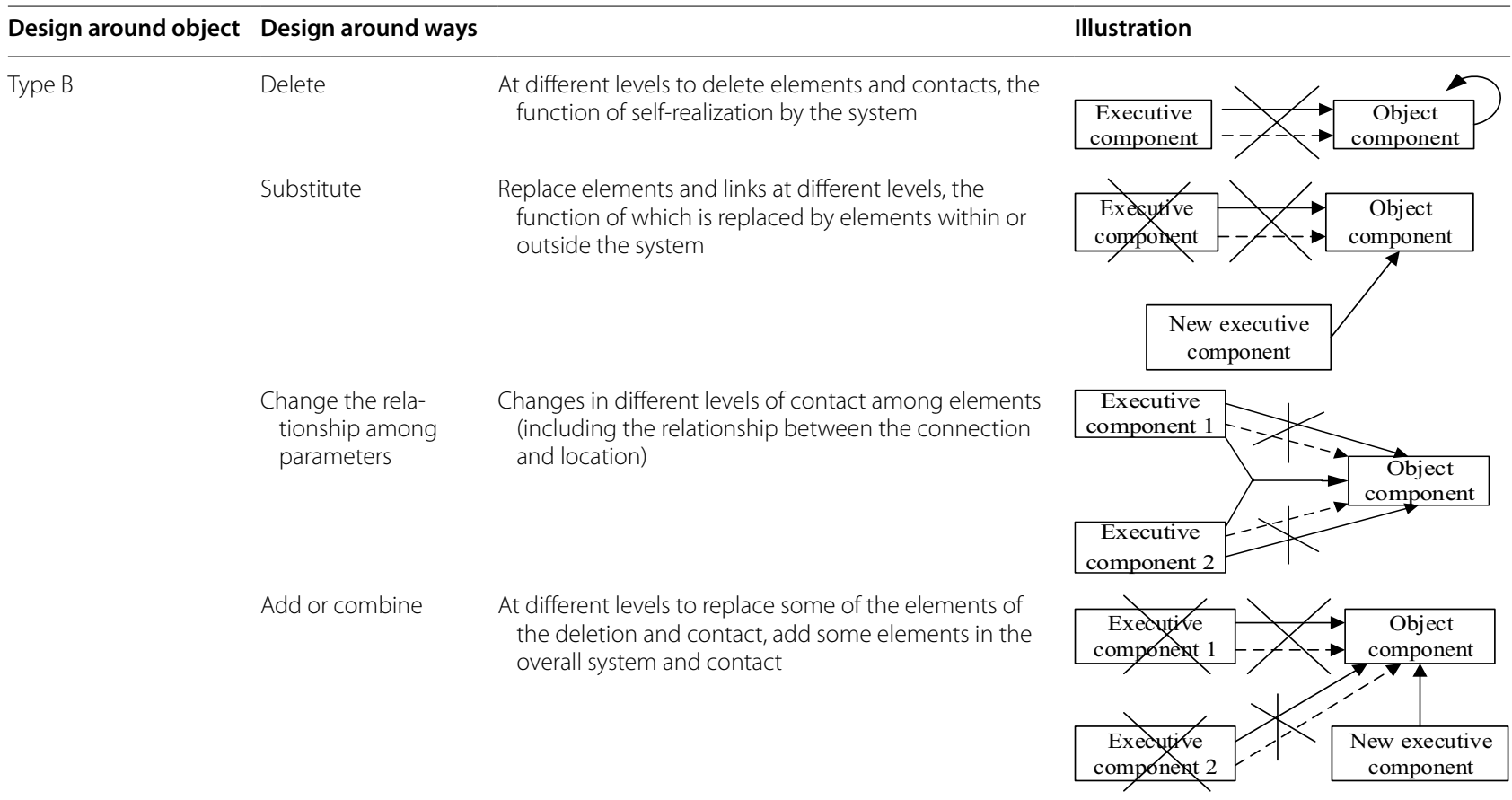

[47]. A specific design can be developed for the final proposal of the design.

If there is no solution reached, the process will go back for redesign in Step 2 described in Section 3.3. Figure 7 shows the TRIZ process for the problem solving based on needs of different technological evolutionary laws and components selected.

\subsection{Evaluation}

Proposed solutions are evaluated for infringement. If there is any infringement, the solution will be denied. If not, it is further checked for patentability from substantive conditions of its validity, creativity, and practical application. A final solution is obtained if it has patentability. In order to obtain the technical protection, the final solution is applied to the patent portfolio. Otherwise, the final solution can be used as knowledge of the enterprise.

\section{Case Study}

\subsection{Selected Product of the Design Around Patent}

A glass-wiping robot is selected as an example for the case study from Patsnap patent database (http://www.

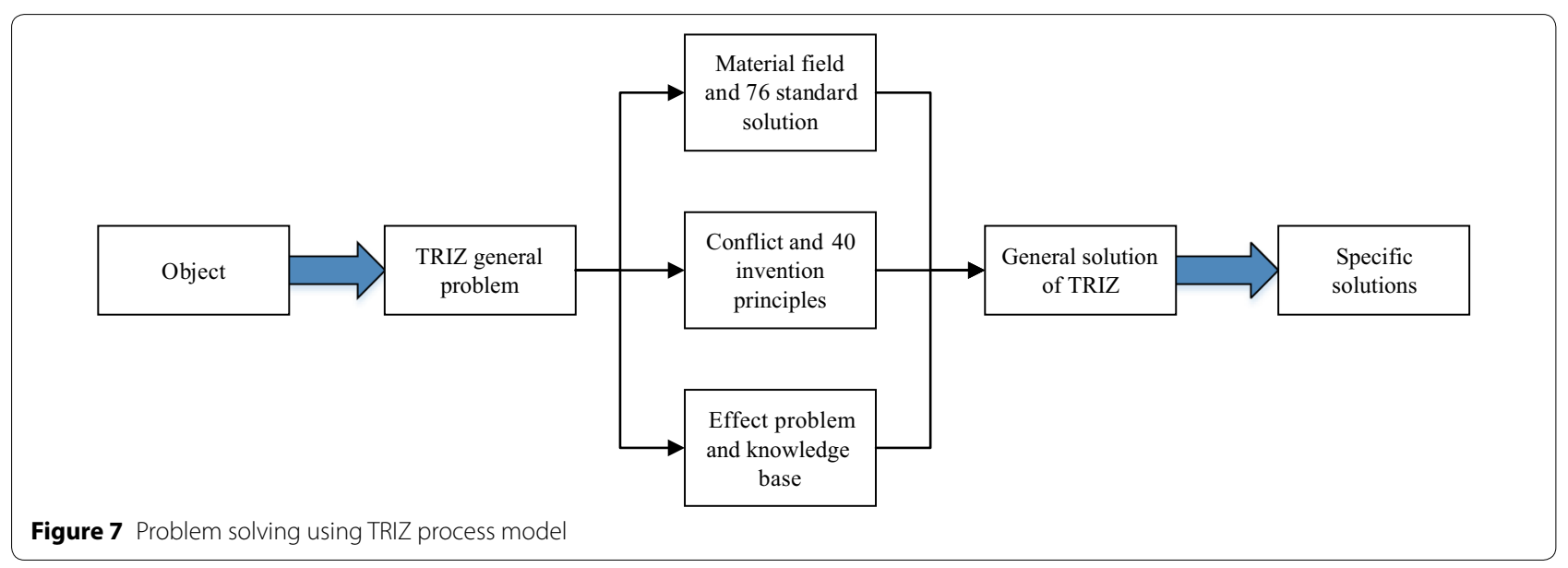


zhihuiya.com) for a product in a leading Chinese company. 148 patents were found. 72 of them were finalized after removing the repetition. Bundle patent portfolios of the glass-wiping robot are obtained through analyzing actual technical problems solved by each patent. They are analyzed in following steps.

1) Patents are classified and marked based on product's functional modules as shown in Figure 8.
2) Technical problems are analyzed for the solution of each patent to perform functions to form problem sets as shown in Table 4. According to technical problems, the patents are classified to form a bundle patent portfolio analysis chart of the glass-wiping robot. Component A has eight bundle patent portfolios. Component B has five, component $\mathrm{C}$ has seven and component $\mathrm{D}$ has four portfolios as shown in Figure 9.

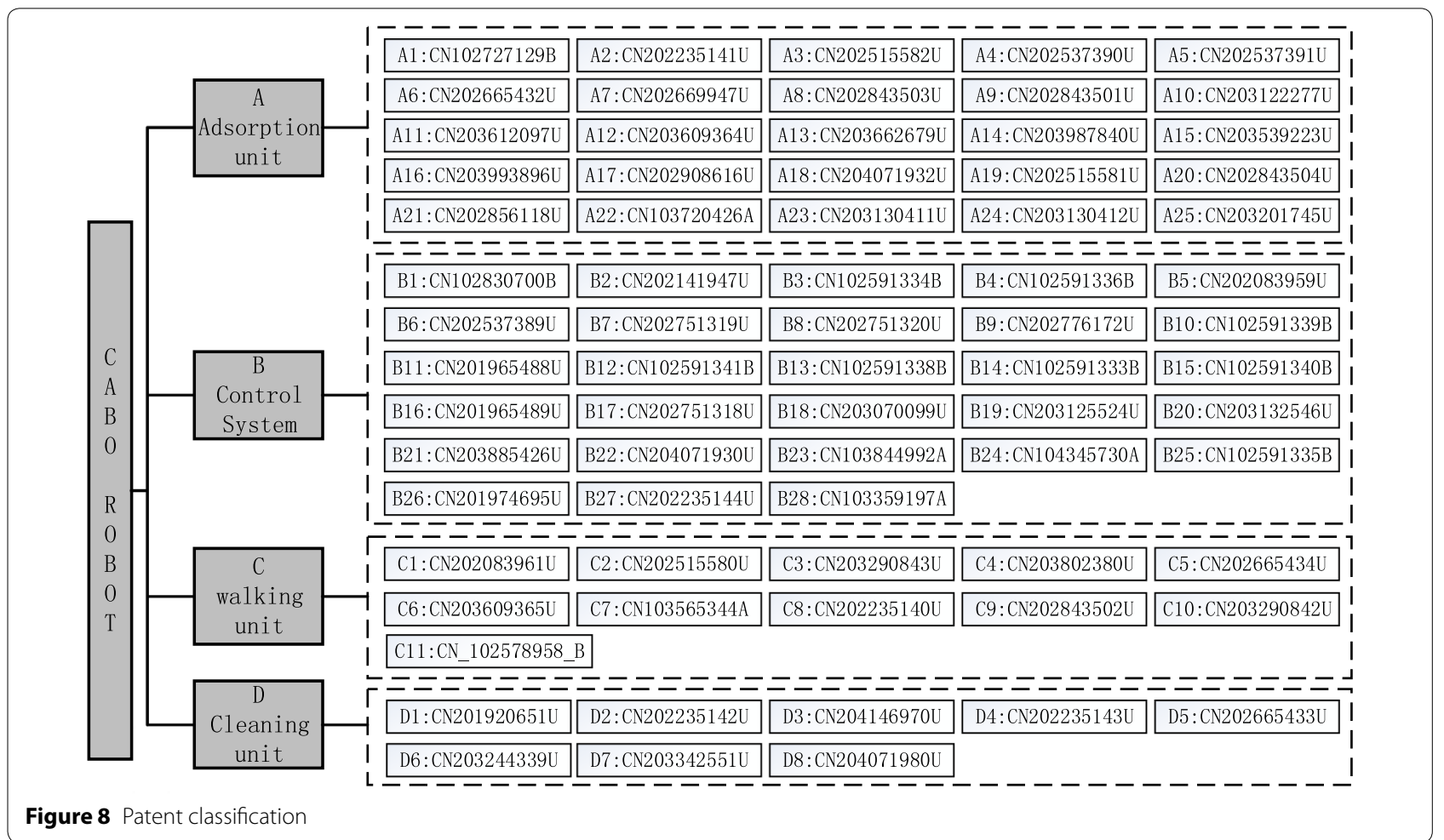

Table 4 Problem sets of product functions

\begin{tabular}{|c|c|c|c|c|}
\hline \multicolumn{3}{|c|}{ Product functions } & \multicolumn{2}{|l|}{ Problem set } \\
\hline \multirow[t]{2}{*}{ A } & $\begin{array}{l}A-T_{1} \text { Double-sided Cabo robot } \\
\text { for different glass thickness }\end{array}$ & $A-T_{2}$ Suction cup sealed & $\mathrm{A}-\mathrm{T}_{3}$ Leakage alarm & $\begin{array}{l}\mathrm{A}-\mathrm{T}_{4} \text { Maintain the balance of } \\
\text { adsorption and friction }\end{array}$ \\
\hline & $\begin{array}{l}\mathrm{A}-\mathrm{T}_{5} \text { Suction cups can be } \\
\text { adjusted to adapt to uneven } \\
\text { surface }\end{array}$ & $\begin{array}{l}A-T_{6} \text { successfully removed the } \\
\text { robot from the window }\end{array}$ & $\begin{array}{l}\mathrm{A}-\mathrm{T}_{7} \text { Adsorption device failure } \\
\text { and other accidental disposal }\end{array}$ & $A-T_{8}$ Suction pump for Cabo robot \\
\hline B & $\begin{array}{l}B-T_{1} \text { Right angle control } \\
B-T_{5} \text { Double-sided wiper control }\end{array}$ & $\mathrm{B}-\mathrm{T}_{2}$ Edge control & $B-T_{3}$ Adjust posture & $B-T_{4}$ Mobile control \\
\hline \multirow[t]{2}{*}{ C } & $\begin{array}{l}\mathrm{C}-\mathrm{T}_{1} \text { Reduce collision plate and } \\
\text { glass window frame friction }\end{array}$ & $\begin{array}{l}\mathrm{C}-\mathrm{T}_{2} \text { Effective implementation } \\
\text { of the cab-glass device walking, } \\
\text { walking smoothly }\end{array}$ & $\begin{array}{l}\mathrm{C}-\mathrm{T}_{3} \text { Adapt to any thickness of } \\
\text { glass }\end{array}$ & $\begin{array}{l}\mathrm{C}-\mathrm{T}_{4} \text { Precise control of the rotation } \\
\text { angle without the need to repeat- } \\
\text { edly adjust the direction of travel }\end{array}$ \\
\hline & $\begin{array}{l}\mathrm{C}-\mathrm{T}_{5} \text { Can't follow the machine in } \\
\text { the window }\end{array}$ & $\begin{array}{l}\mathrm{C}-\mathrm{T}_{6} \text { Power cord interference } \\
\text { when walking. }\end{array}$ & $\begin{array}{l}\mathrm{C}-\mathrm{T}_{7} \text { Work piece free telescopic, } \\
\text { lifting }\end{array}$ & \\
\hline D & $\mathrm{D}-\mathrm{T}_{1}$ Automatic liquid spray & $\mathrm{D}-\mathrm{T}_{2}$ No water stains & $\mathrm{D}-\mathrm{T}_{3}$ Wipe incomplete & $\begin{array}{l}\mathrm{D}-\mathrm{T}_{4} \text { Overcome negative pressure } \\
\text { leaks }\end{array}$ \\
\hline
\end{tabular}


3) For the bundle-type patent portfolio module based on technical constraints, values of the development state of each component under the rule of technological evolution are calculated for adsorption device A, control device $\mathrm{B}$, walking device $\mathrm{C}$ and cleaning device $\mathrm{D}$, respectively, as shown in Table 5 . Values of development state under different technical evolution laws are calculated for components $\mathrm{A}$ and $\mathrm{C}$ shown from the left to right. Components $\mathrm{B}$ and $\mathrm{D}$ are shown from the right to left in Table 5 .

4) A radar chart is formed for the state of product system technology evolution. Product evolutionary state values in Table 5 are shown in a radar chart of Figure 10, the cleaning module represented by the green color shows a less development under laws of the technological evolution.

As shown in Table 4, the cleaning unit of the product solves four problems, namely the liquid spray automation, no water stains, wipe incomplete and negative pressure leaks. In Figure 9, the number of patents for solving these problems is $3,2,2$ and 1 , respectively, forming four types of the beam patent portfolio. The jetting device in the cleaning unit that has a relatively large number of patents is selected as the research object. Bundle-type patent portfolios of the jetting device are CN201920651U, CN203244339U and CN203342551U in Figure 8.

\subsection{Circumventing Problem Identification and Solution Search}

\subsubsection{Forming the Patent Right Map}

Aiming at the bundle patent portfolio of the glass cleaning robot's spraying device, the existing specific schemes of the spraying device of the object enterprise are analyzed. There are manual and mechanical spraying mechanisms as shown in Figures 11 and 12. Among them, the manual injection mechanism requires human to operate the injection, its automation is low, while the mechanical injection mechanism is an automatic push and pressure mechanism composed of the motor, gear and push rod.

For function trimming to identify the problem and break through the technical constraints, a functional model of the mechanical injection mechanism of the object (the patent number CN201920651U) is built to determine the scope of the patent protection as shown in Figure 13.

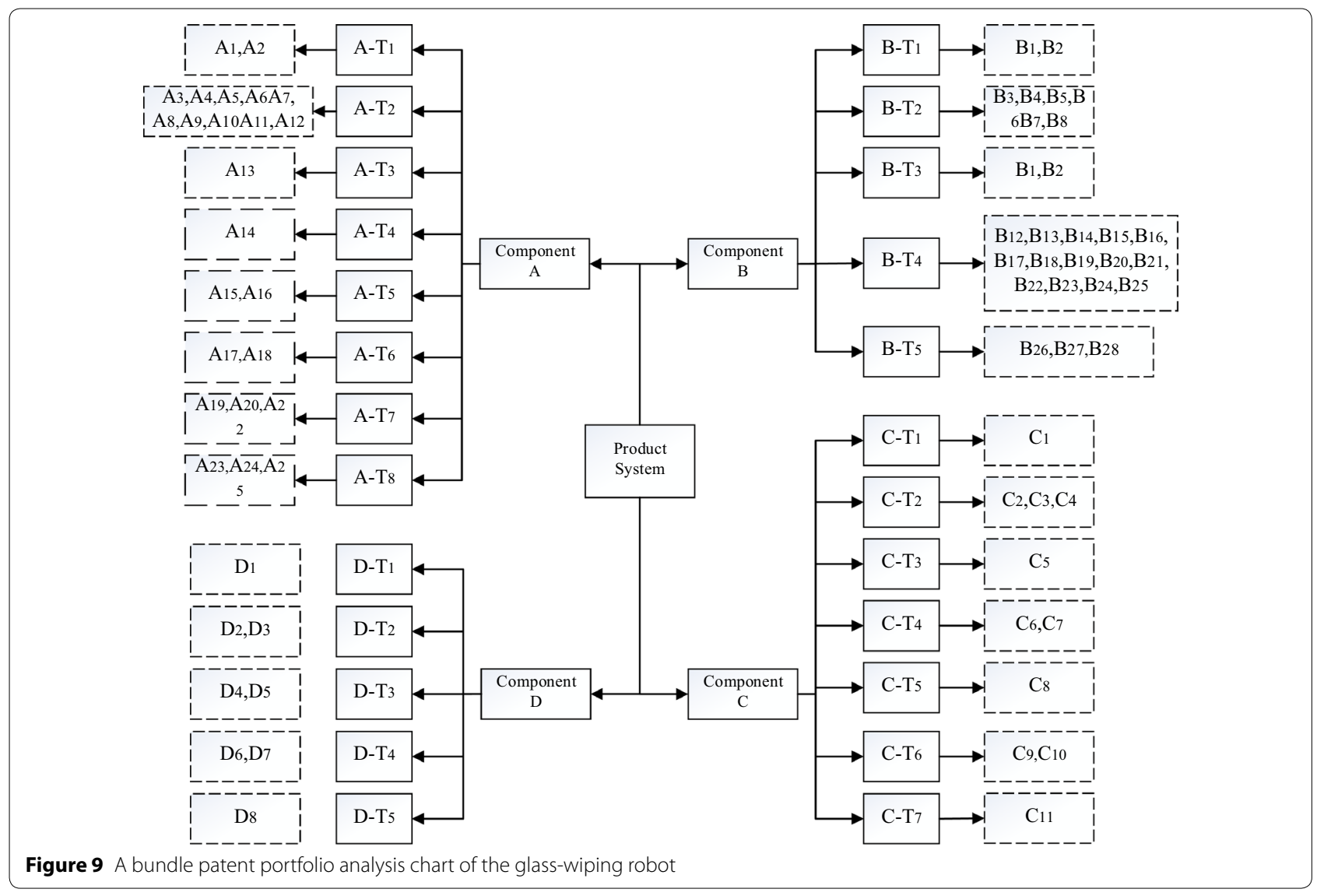




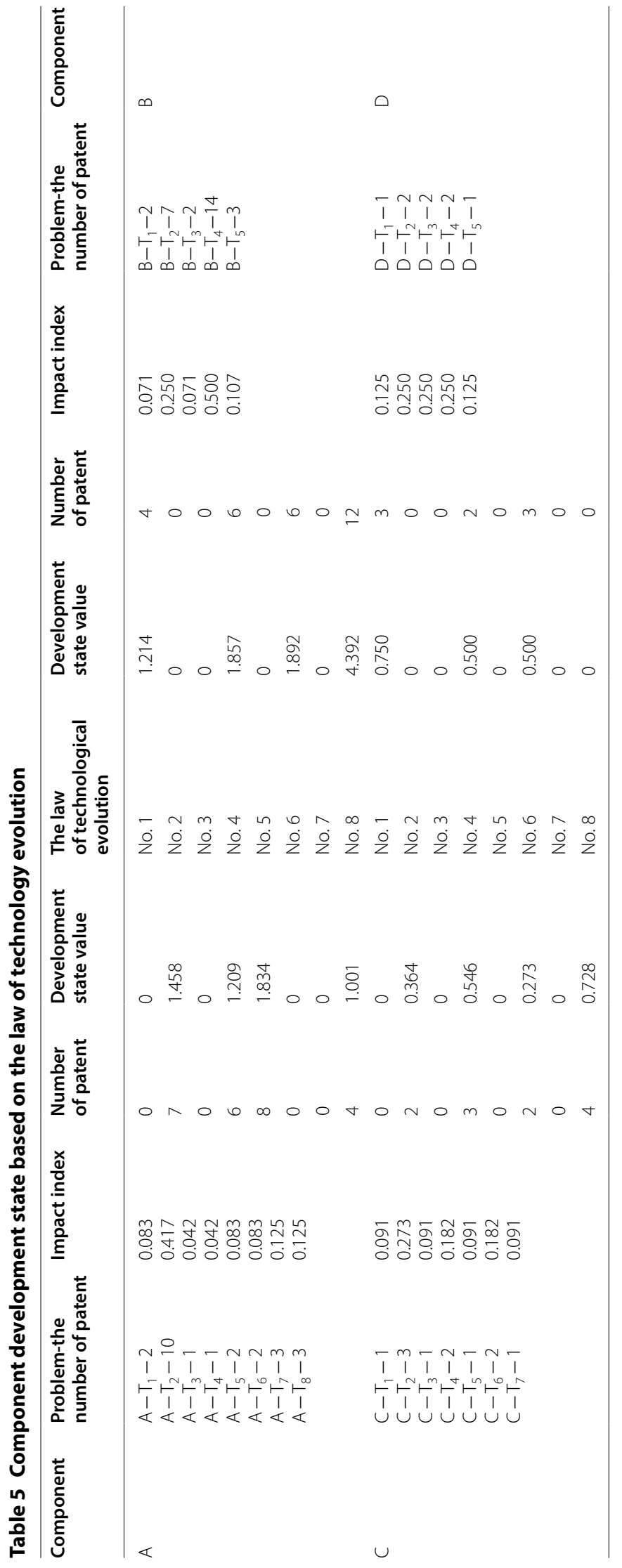




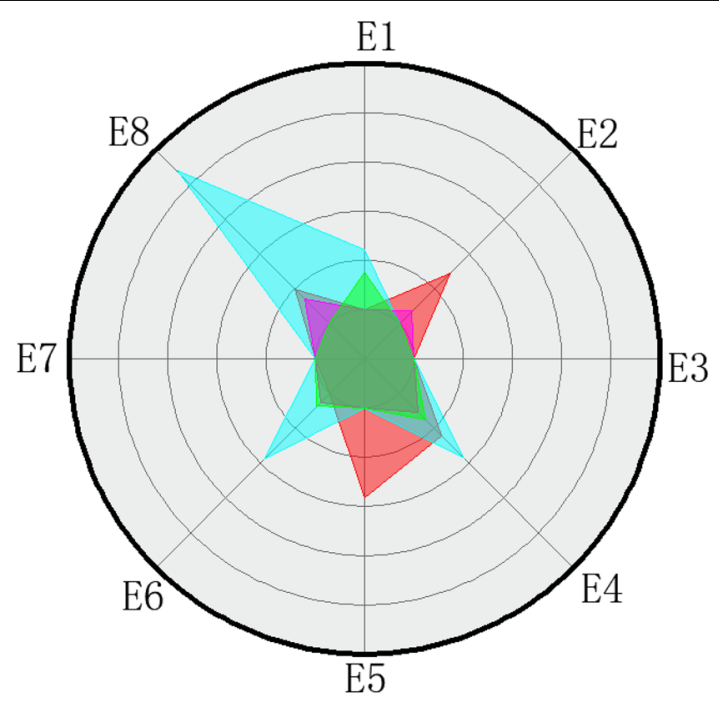

E1: (increasing the idealization leve1)

E2: (the unbalanced development of subsystems)

E3: (Dynamization)

E4: (delivering to a complex system)

E5: (delivering to the microscopic system)

E6: (Integrity)

E7: (shortening the path length of the energy flow)

E8: (increasing the coordination)

-Adsorption unit technology evolution state

Control unit technology evolution state

-Walking unit technology evolution state

Cleaning unit technology evolution state

Figure 10 Radar chart of the robot product evolution

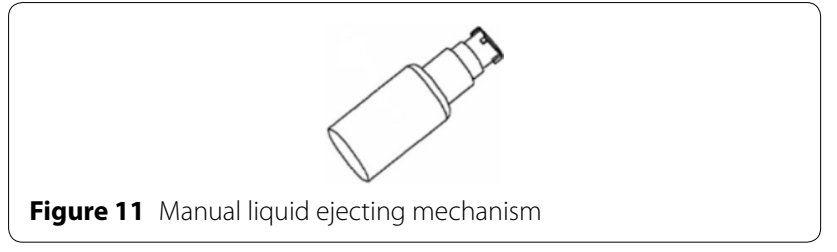

Figure 11 Manual liquid ejecting mechanism

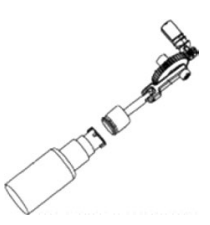

Figure 12 Mechanical liquid ejecting mechanism

\subsubsection{Problem Identification and Solutions}

Scheme 1. According to the development state diagram, we select evolution laws and routes of existing technologies which are less applied to new solutions. The third law of technological evolution is dynamic, in which one route is to transfer the target to a fluid or field as follows: Rigid systems $\rightarrow$ Systems with one hinge $\rightarrow$ Systems with multiple hinges $\rightarrow$ Flexible systems $\rightarrow$ Fluid based systems $\rightarrow$ Field based systems

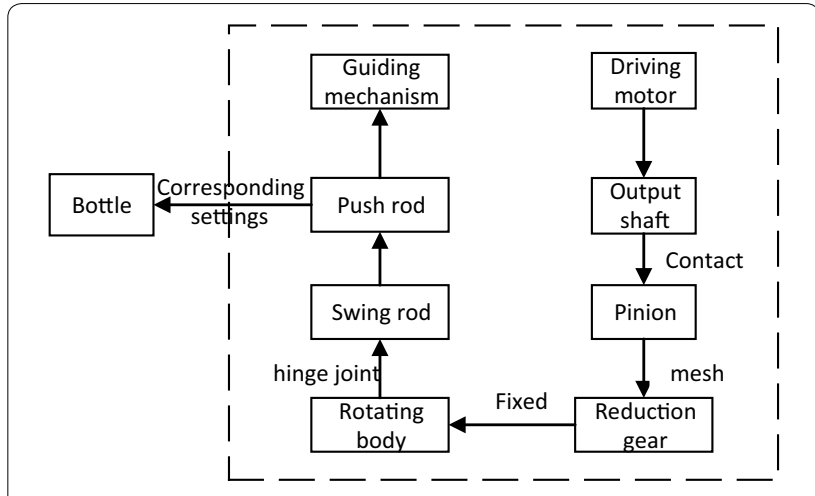

Figure 13 Functional diagram of the liquid ejecting mechanism

[39]. This specific evolutionary route is selected for the technical prediction. Based on the existing product state of competing companies, a specific route search map of the product system is proposed in Figure 14. The current product state is calibrated to predict future product state as a fluid-based system or field-based system. The conceptual solutions for the prediction of future state are listed in Table 6.

From the preliminary search, it is found that concept 1 is invalid as it already exists. Concept 2 is selected for the detail design. Solutions are formed for the electromagnet 


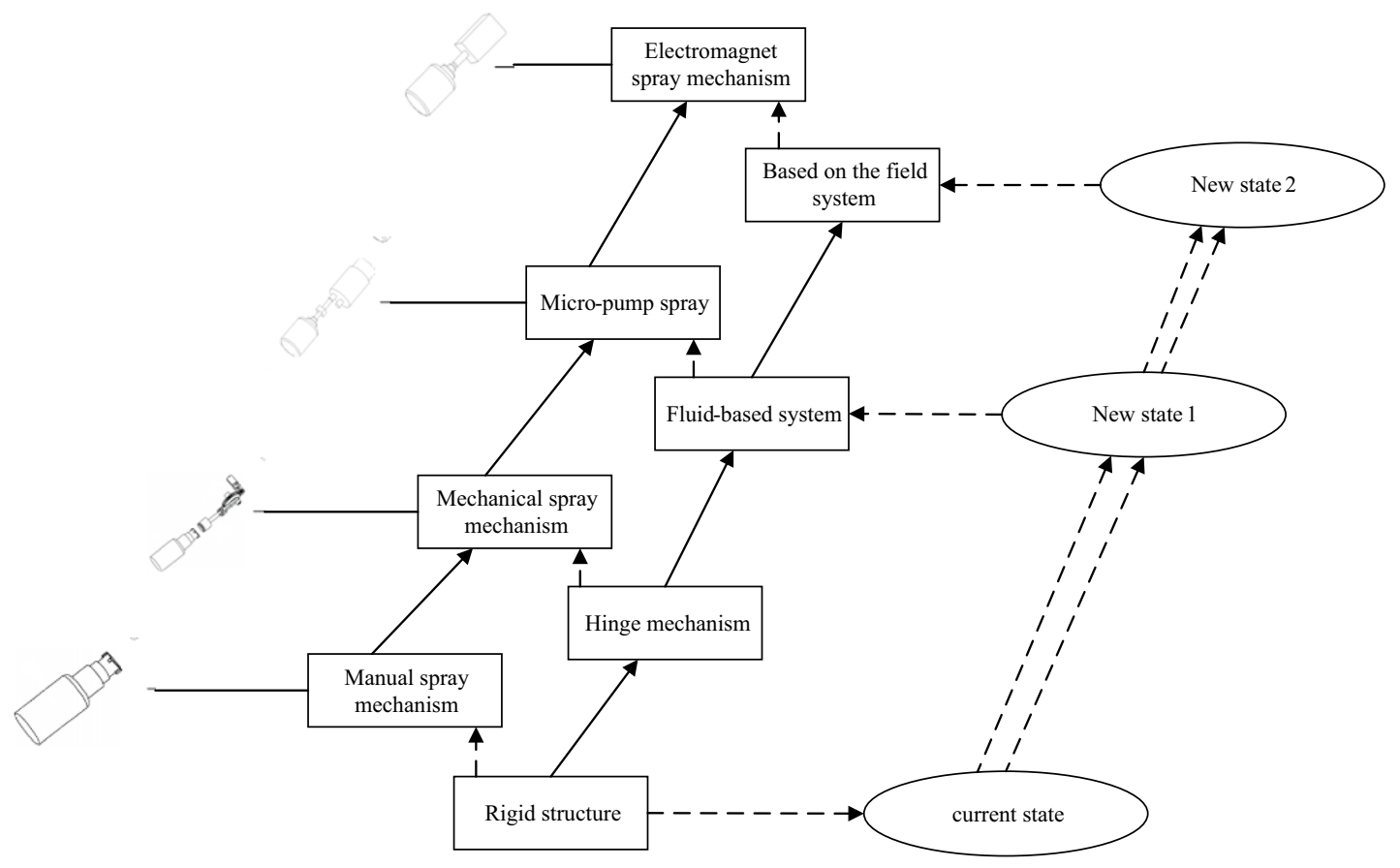

Figure 14 Technology evolution route

\section{Table 6 Conceptual solution based on the roadmap of technological evolution}

\begin{tabular}{ll}
\hline Conceptual plan & Working principle \\
\hline Concept 1 & $\begin{array}{c}\text { Inflation bottles through the micro-pump, when the bottle pressure reaches a } \\
\text { certain level, the liquid will be automatically sprayed. Meet the lightweight and } \\
\text { miniaturization requirements }\end{array}$ \\
Concept 2 & $\begin{array}{l}\text { The use of push-pull electromagnet with automatic reset function can meet the } \\
\text { requirements of lightweight, miniaturization and low noise of the wiping glass } \\
\text { robot }\end{array}$
\end{tabular}

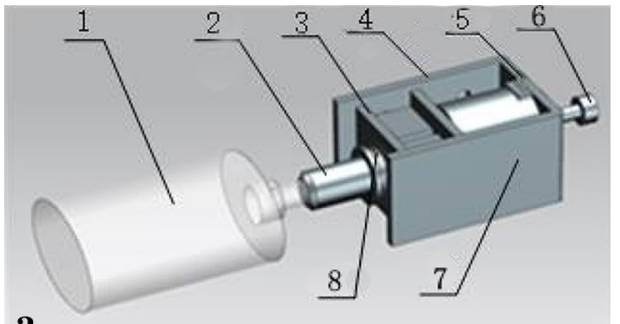

a

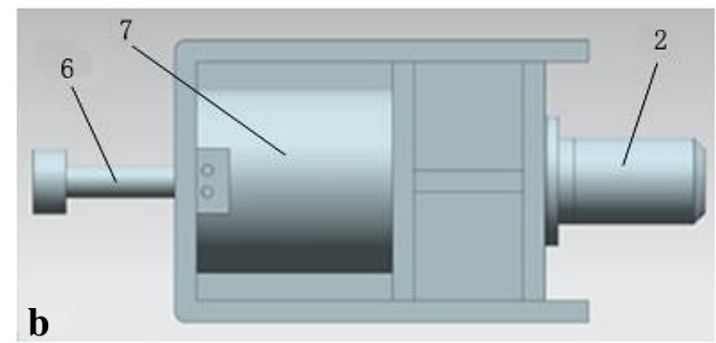

b

Figure 15 Electromagnet spray device: a overall structure, b Power off the state diagram. 1. Bottle, 2. Movable core, 3. Baffle cover, 4. Fixed shell 4, 5. Coil, 6. Fixed iron core, 7. Electromagnet, 8. Spring 


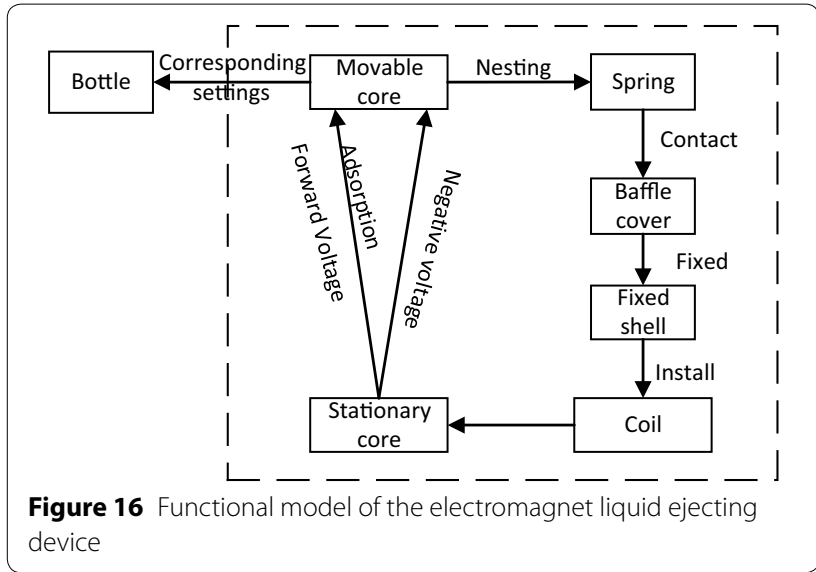

liquid ejecting device as shown in Figure 15. Bottle (1) and electromagnet (7) are mated with the electromagnet through the movable iron core (2) and fixed shell (4). The movable iron core is sleeved with a spring (8) and the other end of the spring is contacted with the baffle cover (3) of the fixed shell. A coil (5) is mounted on the other end of the fixed shell, wherein the fixed iron core (6) is installed inside the coil. Its power-off state is shown in Figure 15(b).

A positive voltage is applied to the electromagnet. The push rod maintains the initial de-energized state and adheres to the fixed iron core. When the voltage is changed, a negative voltage is applied to the electromagnet. The push rod is pushed out of the squeezed bottle to form a liquid jet. Alternating positive and negative voltage can achieve the continuous spray. If there is no need to spray, the electromagnet can be powered off. The push rod can maintain its position without the power consumption for energy-saving.

The electromagnet liquid ejecting device is small in size, simple in structure, and easy in control. Its functional model is shown in Figure 16. The bottle is separated from the robot main body for easy bottle cleaning and replacement. The frequency of positive and negative voltage conversions controls the speed of the liquid spray. When the power is off, it can keep the plunger adsorbed on the fixed iron core for the solenoid stable and highprecision working in a long service life.

Scheme 2. In the second method, the target patent is trimmed and deformed. By replacing the original execution component with the new component, the trimming variant is formed to enlighten the conceptual solution as shown in Figure 17. The problem is converted into the material field as shown in Figure 18. It provides a new solution for implementation of the push mobile function to form a new material field model for

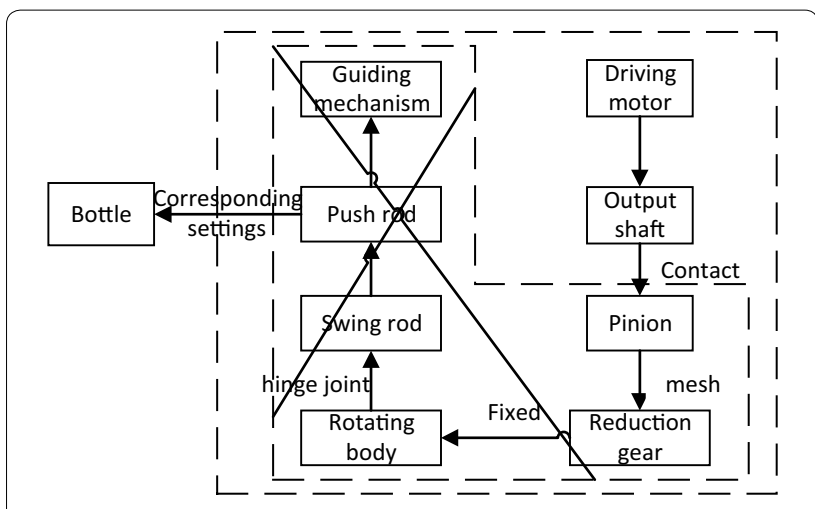

Figure 17 Trimming variant of the jetting device
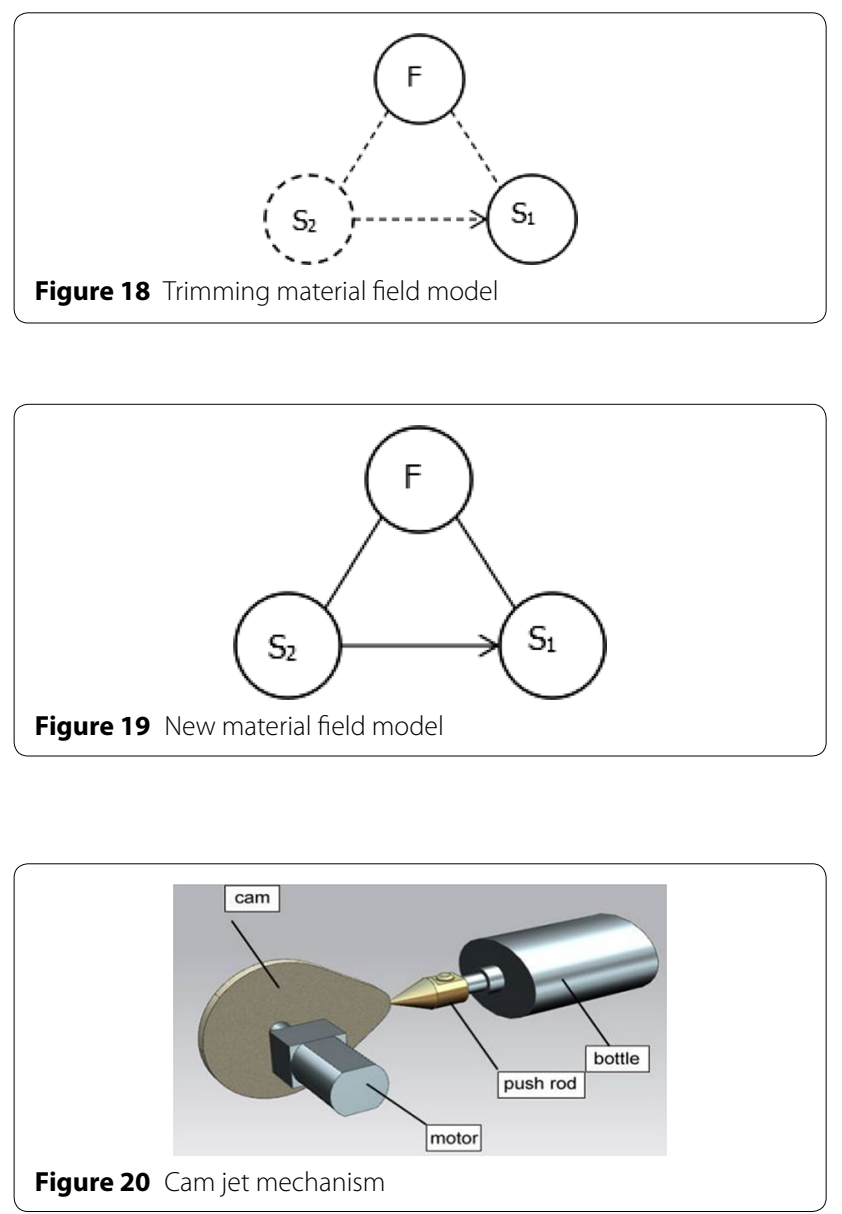

the function design as shown in Figure 19. Using the trimming plan, formed mechanism S2 of the cam jet is composed of a motor, a cam, a push rod and a solution 


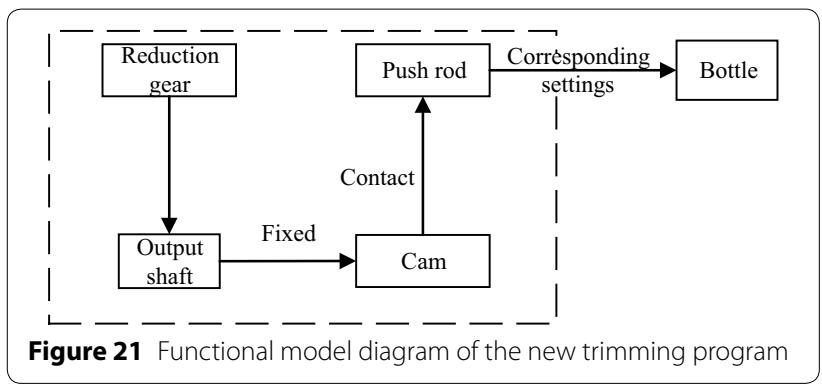

bottle. The cam is driven by a motor. The push rod contacts with the cam for the push function. The push rod stroke can be changed by the shape change of the cam as shown in Figure 20. Compared to the original device, the new scheme has advantages of the simple structure, easy manufacturing and convenient assembling. A functional model of the scheme is shown in Figure 21.

\subsection{Solution Evaluation}

(1) A checklist is established for the infringement judgment in Table 7. It shows that the proposed schemes are non-infringement.

(2) Evaluation of the solution patentability is conducted as shown in Table 8. It is concluded that the proposed schemes are creative and can be patented.

(3) Patent application

As the design of the liquid ejecting device is a new scheme of the original bundle patent-type portfolio. It has the patentability to have the protection value and form the technical solution that competes with the original patent solution. The structure of the cam jet liquid structure is simple and defensive. The proposed electromagnetic automatic liquid ejecting device is creative for the patent application. At present, the proposed scheme has obtained the Chinese utility model patent number ZL201520752490.0 [48]. Its invention patent is under examination.

\subsection{Discussion}

The technology evolution law and trimming methods in TRIZ have been widely used in the design. This research uses the bundle patent portfolio analysis process based on the law of technology evolution to design a cleaning unit of the wiping glass robot. The design results are creative in the following three areas.

1) The bundle patent portfolio analysis helps enterprises allocate resources of research and development. Compared to the traditional process of identifying needs and problems, the advantage of the proposed method can overcome the problem of waste of design resources through understanding of the complete development state of a product. Analyzing state values developed by different components of a product according to different technological evolutionary laws can provide design alternatives for enterprises. For example, from information in Figure 10, the adsorption unit develops rapidly under E1 and E6, slowly on route E8; initial stages of the devel-

Table 7 Infringement judgment checklist

\begin{tabular}{llll}
\hline $\begin{array}{l}\text { Innovative program name } \\
\text { Is it in line with the principle } \\
\text { of universal coverage? }\end{array}$ & $\begin{array}{l}\text { Is consistent with doctrine } \\
\text { of equivalents }\end{array}$ & $\begin{array}{l}\text { Is it in line with the principle } \\
\text { of forbidden regretted } \\
\text { and the principle of donation? }\end{array}$ & $\begin{array}{l}\text { Is it } \\
\text { infringing? } \\
\begin{array}{l}\text { liquid spray device } \\
\text { Cam jet mechanism }\end{array}\end{array}$ \\
\hline
\end{tabular}

Table 8 Evaluation for the solution patentability

\begin{tabular}{|c|c|c|c|c|c|c|}
\hline \multirow{2}{*}{$\begin{array}{l}\text { Innovative program } \\
\text { name }\end{array}$} & \multicolumn{2}{|c|}{ Solve the main technical problems } & \multirow[t]{2}{*}{ Synonyms } & \multirow[t]{2}{*}{ Boolean logic search } & \multirow{2}{*}{$\begin{array}{l}\text { Is there any } \\
\text { novelty? }\end{array}$} & \multirow[t]{2}{*}{ Is it creative? } \\
\hline & The total function & Sub-function & & & & \\
\hline $\begin{array}{l}\text { Electromagnetic } \\
\text { automatic liquid } \\
\text { spray device }\end{array}$ & $\begin{array}{l}\text { Control electromag- } \\
\text { netic to achieve } \\
\text { automatic spray }\end{array}$ & $\begin{array}{l}\text { Electromagnet } \\
\text { push rod device } \\
\text { Bottle }\end{array}$ & $\begin{array}{l}\text { Moveable iron core push rod, } \\
\text { fixed iron core and coil, spring } \\
\text { Push bottle }\end{array}$ & $\begin{array}{l}\text { (Electromagnet push device) or } \\
\text { (moveable iron core push rod) } \\
\text { and (fixed core and coil and } \\
\text { spring) and (spray bottle or } \\
\text { push bottle) }\end{array}$ & Yes & Yes \\
\hline Cam jet mechanism & $\begin{array}{l}\text { Using a cam mecha- } \\
\text { nism to achieve } \\
\text { liquid ejection }\end{array}$ & $\begin{array}{l}\text { Cam mechanism } \\
\text { Spray bottle }\end{array}$ & $\begin{array}{l}\text { Cam, push rod } \\
\text { Spray bottle }\end{array}$ & $\begin{array}{l}\text { (Cam and push rod) or cam } \\
\text { mechanism) and spray bottle }\end{array}$ & Yes & Yes \\
\hline
\end{tabular}


opment are in E3, E4, E7 and E2; the control unit develops rapidly on E8 and E4, and slowly on E7 and E5. Compared to adsorption and control units, the evolution of walking and cleaning units lags behind, especially the cleaning unit. Therefore, the development state under each technology evolution law for the wiping glass robot product is in the initial stage. In this paper, only the cleaning unit is selected for the design. The designer can select different components and technological evolution routes to plan multiple paths, so that the design purpose is clear and the resource allocation is balanced.

2) The analysis of the bundled patent portfolio is more targeted and creative. The bundle patent portfolios formed by three patents CN201920651U, CN203244339U and CN203342551U solving the liquid ejecting problem in this example forms the research object. The right map of the target patent based on the functional model makes the design result meet the scope of the vested rights protection and the design innovation.

3) The design solution that meets requirements of intellectual property rights can be protected by the patent system, as shown in the case example.

\section{Conclusions}

This paper proposed the design around method for a bundle-based patent portfolio based on the law of evolution of technology to obtain alternative solutions of a same problem, aiming at the patented layout of competing firms' products. The method consists of four processes: 1) A radar chart of technology evolutionary state is formed for the bundle-type patent portfolio to find circumvention strategies; 2) Functional evolutionary routes and functional trimming are used to identify the route of problem solving; 3) The TRIZ method is used to search solutions to technical problems; and 4) The solution is evaluated to assess the effectiveness of the method.

Compared to the traditional design methods, the design around patent can make a full use of the patent information, reduce the blindness of innovation, and avoid the patent infringement. Comparing with other methods of design around patent, the proposed method uses a design around of the bundle-type patent portfolio to improve the matching accuracy and adaptability of TRIZ in the solution search based on the patent-based strategy.

\section{Authors' Contributions}

RT was in charge of the whole trial; HL wrote the manuscript; JY assisted with sampling and laboratory analyses. QP improved the paper structure and writing. All authors read and approved the final manuscript.

\section{Authors' Information}

Hui Li, born in 1981, is a research fellow at School of Mechanical Engineering, Hebei University of Technology, and National Technological Innovation Method and Tool Engineering Research Center. Her research interest is in the theory and application of product innovation, Intellectual property and innovative management, especially in research of the patent circumvention and layout design. She has published 9 papers and 1 book, and completed 3 industrial projects. 11 inventive patents have been authorized.

Jiefeng Yuan, born in 1995, is currently a master candidate at School of Mechanical Engineering, Hebei University of Technology, and National Technological Innovation Method and Tool Engineering Research Center.

Runhua Tan, born in 1958, is a professor at School of Mechanical Engineering, Hebei University of Technology, the Director of National Technological innovation Method and Tool Engineering Research Center, the Vice-President of the organization of Computer-Aided Innovation of International Federation for Information Processing in Asia, and Director of Professional Committee of Technological Innovation Method, Chairman of the Chinese Society of TRIZ. His research interests include theory of inventive problem solving (TRIZ), product innovation, conceptual design, and innovation management approaches. He has published more than 80 articles in Journals, such as Computers in Industry, Journal of Innovation and Entrepreneurship, Computers \& Industrial Engineering, and Chinese Journal of Mechanical Engineering. He has published 5 books and completed 24 research projects.

Qingjin Peng is a professor at Department of Mechanical Engineering, University of Manitoba, Canada. He received his bachelor and master degrees in Mechanical Engineering from Xian Jiaotong University, China, and PhD in Mechanical and Manufacturing Engineering from University of Birmingham, UK. His research interests include digital manufacturing, product design, and system modeling and simulation.

\section{Funding}

Supported by National Natural Science Foundation of China (Grant Nos. 51675159, 51605135), Central Guided Local Science and Technology Development Project (Grant No. 1824-1837G), and Ministry of Science and Technology (Grant No. 2017IM040100)

\section{Competing Interests}

The authors declare that they have no competing interests.

\section{Author Details}

${ }^{1}$ National Technical Innovation Method and Tool Engineering Technology Research Center, Hebei University of Technology, Tianjin 300401, China. ${ }^{2}$ The Department of Mechanical Engineering, University of Manitoba, Winnipeg, Canada.

Received: 20 December 2018 Revised: 26 June 2019 Accepted: 12 October 2019

Published online: 25 October 2019

\section{References}

[1] U Lichtenthaler. Intellectual property and open innovation: an empirical analysis. International Journal of Technology Management, 2010, 52: 3-4, 372-391.

[2] B Philipp, N Bastian, S Gerhard. Paving the road to electric vehicles - A patent analysis of the automotive supply industry. Journal of Cleaner Production, 2017, 167: 75-87.

[3] Y S Chen. Using patent analysis to explore corporate growth. Scientometrics, 2011, 88(2): 433-448.

[4] M Kim, C Kim. On a patent analysis method for technological convergence. Procedia Social and Behavioral Sciences, 2012, 40: 657-663.

[5] B Andersen. The hunt for S-shaped growth paths in technological innovation: a patent study. Journal of Evolutionary Economics, 1999, 9(4): 487-526.

[6] E Dubarić, D Giannoccaro, R Bengtsson. Patent data as indicators of wind power technology development. World Patent Information, 2011, 33(2): 144-149. 
[7] Z Tekic, M Drazic, D Kukolj. From patent data to business intelligence PSALM case studies. Procedia Engineering, 2014, 69: 296-303.

[8] E Piacentini, E Drioli, L Giorno. Membrane emulsification technology: Twenty-five years of inventions and research throughpatent survey. Journal of Membrane Science, 2014, 468: 410-422.

[9] B Wang, C H Hsieh. Measuring the value of patents with fuzzy multiple criteria decision making: insight into the practices of the Industrial Technology Research Institute. Technological Forecasting \& Social Change, 2015, 92: 263-275

[10] J E Altwies, G F Nemet. Innovation in the US building sector: An assessment of patent citations in building energy control technology. Energy Policy, 2013, 52: 519-831.

[1 1] S Oh, Z Lei, W C Lee, et al. Patent evaluation based on technological trajectory revealed in relevant prior patents. Lecture Notes in Computer Science, 2014, 8443: 545-556.

[12] T Miyazawa, $\mathrm{H}$ Osada. Evaluation method for nature of basic invention by patent analysis. Portland International Center for Management of Engineering and Technology, 2014: 1:1346-1353.

[13] L Leydesdorff, D Kushnir, I Rafols. Interactive overlay maps for US patent (USPTO) data based on International Patent Classification (IPC). Scientometrics, 2014, 98(3): 1583-1599.

[14] Y L Hsu, P E Hsu, Y C Hung, et al. Development and application of a patent-based design around process. Proceedings of the ASME Design Engineering Technical Conference, 2010, 1: 91-100.

[15] C Q Gao, L M Guo, F L Gao, et al. Innovation design of medical equipment based on TRIZ. Technology and Health Care, 2015, 23(2): S269-S276.

[16] H Park, J Ree, K Kim. Identification of promising patents for technology transfers using TRIZ evolution trends. Expert Systems with Applications, 2012, 40(2): 736-743.

[17] J L Luo, S Y Cheng, X R Yang, et al. The functional analysis and patent circumvention based on Pro/Innovator. Modern Manufacturing Engineering, 2016, 2: 22-28. (in Chinese)

[18] G Kim, J Lee, D Jang, et al. Technology clusters exploration for patent portfolio through patent abstract analysis. Sustainability, 2016, 8(12): 1252.

[19] TSchubert. Assessing the value of patent portfolios: an international country comparison. Scientometrics, 2011, 88(3): 787-804.

[20] H Li. Patent design around research based on mechanical patent's technology constraints and system constraints. Hebei University of Technology, 2016. (in Chinese)

[21] H Li, J T Huo, B Xu, et al. Research on patent portfolio design by using of TRIZ method. Science Technology and Engineering, 2014, 14(36): 197-203. (in Chinese)

[22] $\mathrm{H} \mathrm{Li}, \mathrm{R} H \mathrm{Tan}, \mathrm{BXu}$, et al. Patent design around method based on AFD for umbrella-type patent strategy. Journal of Mechanical Engineering, 2016, 52(5) 1-11. (in Chinese)

[23] G S Altshuller. The innovation algorithm. Worcester, MA: Technical Innovation Center, 2000

[24] R Duran-Novoa, N Leon-Rovira, H Aguayo-Tellez. Inventive problem solving based on dialectical negation, using evolutionary algorithms and TRIZ heuristics. Computers in Industry, 2011, 62(4): 437-445.

[25] L Fiorineschi, F S Frillici, F Rotini. Enhancing functional decomposition and morphology with TRIZ: Literature review. Computers in Industry, 2018, 94: 1-15.

[26] T H J Vaneker, R G J Damgrave, J G Kuster. TRIZ as an enabler for intellectual property protection during product development. Procedia Engineering, 2015, 131: 731-736.

[27] Z Van, F J Julian, W Veldhuijzen, et al. Patent circumvention strategy using TRIZ-based design-around approaches. Procedia Engineering, 2015, 131: 798-806.
[28] J Yoon, W Seo, B Y Coh, et al. Identifying product opportunities using collaborative filtering-based patent analysis. Computers \& Industrial Engineering, 2016, 107: 376-387.

[29] M Li, X Ming, M Zheng, et al. A framework of product innovative design process based on TRIZ and Patent Circumvention. Journal of Engineering Design, 2013, 24(12): 830-848.

[30] M Li, X Ming, L He, et al. A TRIZ-based trimming method for Patent design around. Computer-Aided Design, 2015, 62: 20-30.

[31] T R Chang, C S Wang. Innovative theory and patent-design-around in wheelchair conceptual design. Journal of Gerontechnology and Service Management, 2012, 1(1): 49-62. (in Chinese)

[32] HTChang, CY Chang, W K Wu. Computerized innovation inspired by existing patents. Applied System Innovation for Modern Technology, 2017, ICASI: 1134-1137.

[33] HT Chang, Y C Hsieh, Y P Yang. Approaches to infringement risk evaluation of patent products for design-around. Design Engineering in the Context of Asia, Hong Kong, China, October 29-30, 2015: 110-114.

[34] Y C Hung, Y L Hus. An integrated process for designing around existing patents through TRIZ. Proceedings of the IMECHE Part B Journal of Engineering Manufacture, 2007, 221(1): 109-122.

[35] M Grimaldi, L Cricelli, M D Giovanni. The patent portfolio value analysis: A new framework to leverage patent information for strategic technology planning. Technological Forecasting \& Social Change, 2015, 94(1): 286-302.

[36] P Jiang, C Wang, J G Sun, et al. Method and application of patented design around by combination of IPC cluster analysis and TRIZ. Journal of Mechanical Engineering, 2017, 51(7): 144-154. (in Chinese)

[37] XXXu. Research on patent infringement judgment. China University of Political Science and Law, 2011. (in Chinese)

[38] R H Tan. TRIZ and applications, the process and methods of technological innovation. Beijing: Higher Education Press, 2010. (in Chinese)

[39] H Li, R H Tan, J T Huo, et al. Patent design around based on mechanical patent's technology constraints and system constraints. Computer Integrated Manufacturing System, 2015, 21 (11): 2849-2860. (in Chinese)

[40] R HTan, Q H Zhang. The law and routes of system evolution in TRIZ and the application. Industrial Engineering and Management, 2003, 8(1): 34-36. (in Chinese)

[41] D Cavallucci, C Lerch, E Schenk. Product lines innovation: On the use of technical laws of evolution. In: B H Thierry. The economics of creativity: Ideas, Firms and Markets, London: Routeledge, 2013: 41-57.

[42] H Li, R HTan. Method of patent design around. Beijing: Higher Education Press, 2018. (in Chinese)

[43] D D Sheu, CT Hou. TRIZ-based trimming for process-machine improvements: Slit-valve innovative redesign. Computers \& Industrial Engineering, 2013, 66(3): 555-566.

[44] D Russo, C Rizzi, G Montelisciani. Inventive guidelines for a TRIZ-based eco-design matrix. Journal of Cleaner Production, 2014, 76: 95-105.

[45] J R Chou. An ideation method for generating new product ideas using TRIZ, concept mapping, and fuzzy linguistic evaluation techniques. Advanced Engineering Informatics, 2014, 28(4): 441-454.

[46] Z Pei, E Amira, Z M Cecilia, et al. Experience capitalization to support decision making in inventive problem solving. Computers in Industry, 2018, 101: $25-40$.

[47] G S Altshuller. Creativity as an exact science: The theory of the solution of inventive problems. New York: Gordon and Breach, 1984.

[48] H Li, J H Zhang. A glass cleaning robot: CHINA, 205018965U.2015-09-23. http://www.soopat.com/Patent/201520752490. 